\title{
Epigenetic and gene expression changes of neuronal cells from MSA patients are pronounced in enzymes for cell metabolism and calcium-regulated protein kinases
}

\author{
Laura de Boni $^{1}$ (D) Gilles Gasparoni ${ }^{2} \cdot$ Anna Welle $^{2} \cdot$ Sascha Tierling $^{2} \cdot$ Ina Schmitt $^{1} \cdot$ Jörn Walter $^{2} \cdot$ Jochen Walter $^{1}$. \\ Ullrich Wüllner ${ }^{1}$
}

Received: 17 June 2021 / Revised: 3 August 2021 / Accepted: 4 August 2021 / Published online: 9 August 2021

(c) The Author(s) 2021

In 2020, Bettencourt et al. [1] investigated total DNA methylation alterations in white matter from patients with Multiple System Atrophy (MSA). They identified HIP1, LMAN2 and $M O B P$ amongst the most differentially methylated loci. However, MSA is not only characterised by abnormal Glial Cytoplasmic Inclusions (GCIs) but also Neuronal Cytoplasmic Inclusions (NCIs) containing the $\alpha$-synuclein $(\alpha \mathrm{SYN})$ protein $[3,4]$. Despite the extensive neuropathological characterisation and the identification of genetic risk loci, the pathogenesis of MSA remains largely unknown [2]. Novel genetic or epigenetic clues of white and grey matter gene regulation in MSA patients linked to the pathophysiology are, therefore, urgently needed for a better understanding of the pathogenesis.

To address this issue and in addition to the aforementioned study, we carried out a total DNA methylation analysis (EPIC array, Illumina) covering $850 \mathrm{~K} \mathrm{CpGs}$ in the genome of FACS-sorted NeuN-positive neuronal nuclei from the occipital cortex (OC) of MSA patients and controls (Material and Methods, online resource; Table 1, online resource). We chose this low affected brain region in MSA patients to detect presumed pre-existing, possible diseasecausing epigenetic changes leaving out epigenetic changes due to the disease itself.

Most of the top $10 \mathrm{~K}$ ranking CpGs $(n=9638)$ using a combined rank analysis (see online resource for material and methods) were hypermethylated in MSA patients compared to controls (Fig. 1a, b). The majority of those hypermethylated CpGs was located at gene bodies $(n=3440$,

Laura de Boni

laura.deboni@ukbonn.de

1 Department of Neurology, University Hospital Bonn, Venusberg-Campus 1, Bonn, Germany

2 Department of Genetics/Epigenetics, Saarland University, Campus Saarbrücken, Building A2 4, Saarbrücken, Germany
$36 \%$ ), intergenic regions (not annotated, $n=2601,27 \%$ ) and upstream of transcription start site (TSS) $1500(n=1725$, $18 \%$, Fig. 1c). Hypomethylated CpGs in MSA patients were mainly located in gene bodies ( $n=108,30 \%$, Fig. 1c). GO analysis based on these top $10 \mathrm{~K}$ ranking $\mathrm{CpGs}$ identified several $\mathrm{CpGs}$ enriched in the biological processes and molecular function of guanosinetriphosphatase activity and adenosinetriphosphatase coupled to transmembrane transporter activity (Fig. 1d). Cellular components showed an enrichment of the septin protein family and pathways of calcium signalling (Fig. 1d). As not all CpGs of a respective gene are represented on the EPIC array, we evaluated which genes in the top $10 \mathrm{k}$ ranking $\mathrm{CpGs}$ are significantly enriched in the dataset according to their number of $\mathrm{CpGs}$ on the array and the overall number of $\mathrm{CpGs}$ on the gene. Thus, we identified the enriched significant genes in the top $10 \mathrm{k}$ data set according to the combined rank value. The majority of these genes in the top 20 were associated with inflammatory/immune responses and transcriptional regulation ( $n=7$, Table 2, online resource). Interestingly, all CpGs of the top 20 genes were hypermethylated in MSA patients independently of their location on the gene (Table 2, online resource).

Comparing our array-based top $10 \mathrm{~K}$ ranked neuronal CpGs to array-based transcriptomic data from MSA patients and controls (Affymetrix human genome U133, Thermo Fisher Scientific, Table 3, online resource), we identified 34 genes with overlapping $\mathrm{CpGs}$ and differentially expressed genes (DEG) in the grey matter (GM) of the OC (Table 4, online resource). All CpGs were hypermethylated in MSA patients and 28 of 34 corresponding genes were downregulated (Table 4, online resource). GO analysis of our top $10 \mathrm{~K}$ CpG ranked dataset showed an overlap of hypermethylated CpGs and upregulated DEGs associated with voltage-gated calcium channel complexes $(p=2.6 \mathrm{E}-6)$ and calcium channel complexes $(p=2.4 \mathrm{E}-5)$. According to the number of 
a

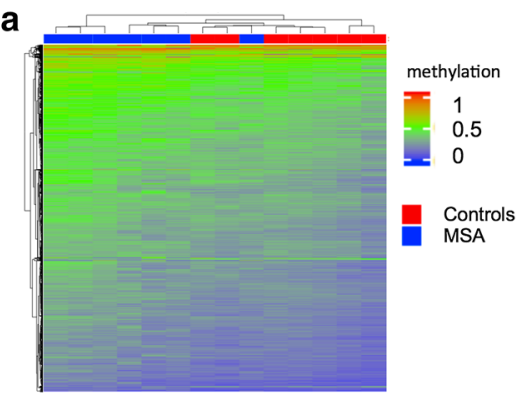

b
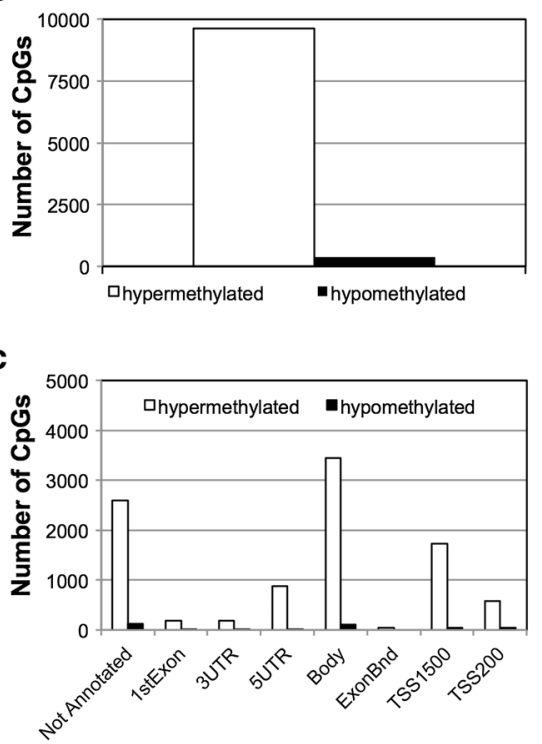

d

\begin{tabular}{|c|c|c|c|c|}
\hline Ontology & Go term & Description & P-value & FDR q-value \\
\hline Biological process & G0:0043547 & positive regulation of GTPase activity & $8.95 \mathrm{E}-11$ & $9.95 \mathrm{E}-7$ \\
\hline Biological process & 60:0051056 & regulation of small GTPase mediated signal transduction & $2.01 \mathrm{E}-10$ & $1.12 \mathrm{E}-6$ \\
\hline Biological process & G0:0043087 & regulation of GTPase activity & $7.05 E-10$ & $2.61 E-6$ \\
\hline Biological process & 60:1901564 & organonitrogen compound metabolic process & $1.31 \mathrm{E}-9$ & $3.65 \mathrm{E}-6$ \\
\hline Biological process & 60:0008152 & metabolic process & $3.36 \mathrm{E}-9$ & $7.48 \mathrm{E}-6$ \\
\hline Biological process & 60:1902600 & proton transmembrane transport & 3.54E-9 & $6.57 \mathrm{E}-6$ \\
\hline Biological process & 60:0071704 & organic substance metabolic process & $5.16 \mathrm{E}-9$ & $8.19 \mathrm{E}-6$ \\
\hline Biological process & 60:0044238 & primary metabolic process & $2.6 \mathrm{E}-8$ & $3.61 \mathrm{E}-5$ \\
\hline Biological process & 60:1903522 & regulation of blood circulation & $4 E-8$ & $4.95 E-5$ \\
\hline Biological process & 60:0044281 & small molecule metabolic process & $5.69 E-8$ & $6.33 E-5$ \\
\hline Molecular function & 60:0043492 & ATPase activity, coupled to movement of substances & $1.37 \mathrm{E}-27$ & $3.72 E-24$ \\
\hline Molecular function & 60:0015399 & primary active transmembrane transporter activity & $1.78 \mathrm{E}-26$ & $2.43 \mathrm{E}-23$ \\
\hline Molecular function & G0:0015405 & P-P-bond-hydrolysis-driven transmembrane transporter activity & $1.78 \mathrm{E}-26$ & $1.62 \mathrm{E}-23$ \\
\hline Molecular function & 60:0042626 & ATPase activity, coupled to transmembrane movement of substances & $1.78 \mathrm{E}-26$ & $1.21 \mathrm{E}-23$ \\
\hline Molecular function & 60:0004222 & metalloendopeptidase activity & $2.45 \mathrm{E}-21$ & $1.33 \mathrm{E}-18$ \\
\hline Molecular function & 60:0022853 & active ion transmembrane transporter activity & $8.98 \mathrm{E}-20$ & $4.07 E-17$ \\
\hline Molecular function & 60:0042625 & ATPase coupled ion transmembrane transporter activity & $8.98 \mathrm{E}-20$ & $3.49 \mathrm{E}-17$ \\
\hline Molecular function & 60:0019829 & cation-transporting ATPase activity & $8.98 \mathrm{E}-20$ & $3.05 E-17$ \\
\hline Molecular function & 60:0008237 & metallopeptidase activity & $4.36 \mathrm{E}-19$ & $1.32 \mathrm{E}-16$ \\
\hline Molecular function & 60:0016787 & hydrolase activity & $1.37 E-16$ & $3.73 \mathrm{E}-14$ \\
\hline Cellular component & 60:0005581 & collagen trimer & $1.17 \mathrm{E}-11$ & $1.64 \mathrm{E}-8$ \\
\hline Cellular component & 60:0032156 & septin cytoskeleton & $1.36 \mathrm{E}-11$ & $9.55 \mathrm{E}-9$ \\
\hline Cellular component & 60:0032153 & cell division site & $1.36 \mathrm{E}-11$ & $6.36 \mathrm{E}-9$ \\
\hline Cellular component & 60:0031105 & septin complex & $1.36 \mathrm{E}-11$ & $4.77 \mathrm{E}-9$ \\
\hline Cellular component & G0:0005940 & septin ring & $1.36 \mathrm{E}-11$ & $3.82 E-9$ \\
\hline Cellular component & 60:0034704 & calcium channel complex & $5.8 \mathrm{E}-11$ & $1.35 \mathrm{E}-8$ \\
\hline Cellular component & 60:0005891 & voltage-gated calcium channel complex & $2.82 \mathrm{E}-10$ & $5.64 \mathrm{E}-8$ \\
\hline Cellular component & 60:0016469 & proton-transporting two-sector ATPase complex & $3.58 \mathrm{E}-9$ & $6.27 E-7$ \\
\hline Cellular component & 60:0016342 & catenin complex & $6.06 \mathrm{E}-7$ & $9.43 E-5$ \\
\hline Cellular component & GO:1990454 & L-type voltage-gated calcium channel complex & $6.92 \mathrm{E}-7$ & $9.7 E-5$ \\
\hline
\end{tabular}

\section{e}

EPIC array, total methylation analysis, FACS-sorted NeuN-positive neuronal nuclei, Affymetrix human genome MSA vs. Ctrls.

\begin{tabular}{|llllllllll|} 
Gene & Region & $\begin{array}{l}\text { Number } \\
\text { CpGs on } \\
\text { EPIC } \\
\text { array }\end{array}$ & $\begin{array}{l}\text { Number } \\
\text { CpGs } \\
\text { gene } \\
\text { body }\end{array}$ & $\begin{array}{l}\text { Methylation } \\
\text { of all CpGs }\end{array}$ & $\begin{array}{l}\text { Mean } \\
\text { Delta } \\
\text { beta }\end{array}$ & $\begin{array}{l}\text { Fisher } \\
\text { p-value } \\
\text { fdr }\end{array}$ & Region & $\begin{array}{l}\text { Expre- } \\
\text { ssion } \\
\text { M-value }\end{array}$ & $\begin{array}{l}\text { P-adj. } \\
\text {-value }\end{array}$ \\
\hline CAMK2A & OC & 5 & 5 & $\begin{array}{l}\text { Hyper- } \\
\text { methylated }\end{array}$ & 0.06 & 0.03 & OC & 1 & 0.04 \\
\hline
\end{tabular}

Fig. 1 DNA methylation and gene expression analysis in FACSsorted neurons from MSA patients and healthy controls. a Methylation heatmap for the top $10 \mathrm{~K}$ ranking $\mathrm{CpGs}$ according to the combined rank metrics from RnBeads. b Number of hypermethylated and hypomethylated CpGs from the top $10 \mathrm{~K}$ CpGs in MSA patients compared to controls. $\mathbf{c}$ Distribution of the top $10 \mathrm{~K} \mathrm{CpGs}$ at genomic annotations. Ctrl. control, ExonBnd exon boundaries, TSS transcription start site, UTR untranslated region. d Top 10 GO enriched terms of each ontology group of the top $10 \mathrm{~K}$ ranked $\mathrm{CpGs}$ from the

CpGs linked to a specific gene and the number of $\mathrm{CpGs}$ represented on the EPIC array, only one overlapping hypermethylated $\mathrm{CpG}$ /upregulated DEG pair (located at the gene body), CAMK2A, could be identified (Fig. 1e).

When comparing the top $10 \mathrm{~K} \mathrm{CpGs} \mathrm{of} \mathrm{the} \mathrm{present}$ study to the study of Bettencourt et al. [1] who analysed total methylation in white matter (WM) tissue of MSA patients (Table 5 , online resource), only three overlapping genes (Table 6, online resource) were identified. In contrast, Rydbirk et al. studied 5-methylcytosine and 5-hydroxymethylcytosine separately in bulk brain tissue from MSA patients (Table 5, online resource) [7] and 17 CpGs located on 12 genes overlapped with our $10 \mathrm{~K} \mathrm{CpGs} \mathrm{(Table} \mathrm{7,} \mathrm{online}$ resource). However, AREL1, the main locus identified in
DNA methylation analysis of NeuN-positive neuronal nuclei. e Overlap of CpGs and DEGs according to the number of $\mathrm{CpGs}$ present on the EPIC array of a respective gene corrected for the overall number of CpGs on the gene. Ctrls. controls, $p$-adj. p-value $p$-adjusted $p$-value, $O C$ occipital cortex, $G M$ grey matter, $5 m C$ 5-methylcytosine, $f d r$ false discovery rate. Data analysis is based on a Bayesian model calculation of the m-value. $\mathrm{M}+1=$ increased expression, twofold change of mean expression

the study of Rydbirk et al. was not present in our top $10 \mathrm{~K}$ dataset of neuronal preparations. Overall, these comparisons demonstrate the cell-type-specific DNA methylation differences in MSA patients and the necessity to analyse tissue-specific preparations.

We also evaluated two other MSA transcriptomic studies (Table 5, online resource) [5, 6]: Piras et al. investigated WM of the cerebellum (CE) and laser-microdissected (LCM) oligodendrocytes. Mills et al. focussed on DEGs upregulated in WM vs. GM and GM vs. WM of MSA patients. Comparing our DEG dataset with DEGs from the study of Piras et al., only one overlapping DEG, Notch2, which was downregulated twofold in GM (p adj. p-value 0.03) and upregulated in WM $(\log 2$-fold 0.7 , p adj. p-value 0.04$)$ was identified. 
Comparing our own GM DEGs from the occipital cortex to GM DEGs from frontal cortex of the study from Mills et al., we only identified seven overlapping DEGs including $C A M K K 2$ which was differentially regulated in the brain regions (Table 8 , online resource).

To summarise, our study, although performed with a small sample size, clearly demonstrates distinct DNA methylation and gene expression changes in neurons from MSA patients. Our comparative analyses of recently published data, albeit with different study designs and statistical analysis on DNA methylation and transcriptomics in MSA patients, showed that MSA patients not only exhibit specific differences in epigenetic and gene expression regulation compared to controls, but also between neuronal and glial cells. Thus, it will be necessary shed further light on epigenetic and gene expression analysis in post-mortem brain tissue comparing grey and white matter alterations between different MSA subtypes in different brain regions.

Supplementary Information The online version contains supplementary material available at https://doi.org/10.1007/s00401-021-02357-5.

Funding Open Access funding enabled and organized by Projekt DEAL. This research was funded by the Thiemann foundation, grant no [2018], BMBF/ANR through EPIPD, grant no [01KU1403B], EU/ EFPIA innovative medicines initiative joint undertaking Aetionomy, grant no [15568], Deutsche Parkinson Vereinigung.

Open Access This article is licensed under a Creative Commons Attribution 4.0 International License, which permits use, sharing, adaptation, distribution and reproduction in any medium or format, as long as you give appropriate credit to the original author(s) and the source, provide a link to the Creative Commons licence, and indicate if changes were made. The images or other third party material in this article are included in the article's Creative Commons licence, unless indicated otherwise in a credit line to the material. If material is not included in the article's Creative Commons licence and your intended use is not permitted by statutory regulation or exceeds the permitted use, you will need to obtain permission directly from the copyright holder. To view a copy of this licence, visit http://creativecommons.org/licenses/by/4.0/.

\section{References}

1. Bettencourt C, Foti SC, Miki Y, Botia J, Chatterjee A, Warner TT et al (2020) White matter DNA methylation profiling reveals deregulation of HIP1, LMAN2, MOBP, and other loci in multiple system atrophy. Acta Neuropathol 139:135-156. https://doi.org/ 10.1007/s00401-019-02074-0

2. Federoff M, Schottlaender LV, Houlden H, Singleton A (2015) Multiple system atrophy: the application of genetics in understanding etiology. Clin Auton Res 25:19-36. https://doi.org/10. 1007/s10286-014-0267-5

3. Koga S, Dickson DW (2018) Recent advances in neuropathology, biomarkers and therapeutic approach of multiple system atrophy. J Neurol Neurosurg Psychiatry 89:175-184. https://doi.org/10. 1136/jnnp-2017-315813

4. Krismer F, Wenning GK (2017) Multiple system atrophy: insights into a rare and debilitating movement disorder. Nat Rev Neurol 13:232-243. https://doi.org/10.1038/nrneurol.2017.26

5. Mills JD, Kim WS, Halliday GM, Janitz M (2015) Transcriptome analysis of grey and white matter cortical tissue in multiple system atrophy. Neurogenetics 16:107-122. https://doi.org/10.1007/ s10048-014-0430-0

6. Piras IS, Bleul C, Schrauwen I, Talboom J, Llaci L, De Both MD et al (2020) Transcriptional profiling of multiple system atrophy cerebellar tissue highlights differences between the parkinsonian and cerebellar sub-types of the disease. Acta Neuropathol Commun 8:76. https://doi.org/10.1186/s40478-020-00950-5

7. Rydbirk R, Folke J, Busato F, Roché E, Chauhan AS, Løkkegaard A et al (2020) Epigenetic modulation of AREL1 and increased HLA expression in brains of multiple system atrophy patients. Acta Neuropathol Commun 8:29. https://doi.org/10.1186/ s40478-020-00908-7

Publisher's Note Springer Nature remains neutral with regard to jurisdictional claims in published maps and institutional affiliations. 